\title{
Sustainable fabrication of zeolitic imidazolate framework-67 membrane via supercritical fluid processing of Co-based gel layer
}

Liangliang Liu, Mu Zhang, Taotao Ji, Jiahui Yan, Yanwei Sun, Gaohong He and Yi Liu*

State Key Laboratory of Fine Chemicals, School of Chemical Engineering, Dalian University of Technology, Linggong

Road No. 2, Ganjingzi District, Dalian 116024, China

*E-mail: diligenliu@dlut.edu.cn 
SI-1 Characterization of porous $\alpha-\mathrm{Al}_{2} \mathrm{O}_{3}$ substrate

SI-2 Characterization of Co-based gel layer obtained by drying at $120^{\circ} \mathrm{C}$

SI-3 Plausible chemical reactions occurring in Co-based gel layer

SI-4 Characterization of ZIF-67 membrane prepared by in situ supercritical growth in $\mathrm{scCO}_{2}$ environments

SI-5 Preparation of ZIF-67 membrane via solution-based protocol

SI-6 Characterization of ZIF-67 layer obtained by conventional solution-based protocol

SI-7 Investigation of structural stability of Co-based gel powders under mild reaction conditions

SI-8 Gas separation performance of ZIF-67 membrane as a function of operating temperature

SI-9 Long-term stability of prepared ZIF-67 membrane

SI-10 Characterization of ZIF-67 membranes obtained by in situ supercritical growth in $\mathrm{scCO}_{2}$ environments with recovered 2-mIm powders

SI-11 Characterization of recovered 2-mIm powders

SI-12 Characterization of Co-based gel layer drying at room temperature

SI-13 Characterization of Co-based gel layer drying at $240{ }^{\circ} \mathrm{C}$

SI-14 Characterization of ZIF-67 membranes obtained with Co-based gel layers drying at different temperature

SI-15 Characterization of ZIF-67 membranes obtained with different SCF processing temperature 
SI-16 Characterization of ZIF-67 membranes obtained with different SCF processing pressure

SI-17 Viscosity of $\mathrm{scCO}_{2}$ as a function of temperature and pressure

SI-18 Gas separation performances of ZIF-67 membranes in the literature 


\section{SI-1 Characterization of porous $\alpha-\mathrm{Al}_{2} \mathrm{O}_{3}$ substrate}

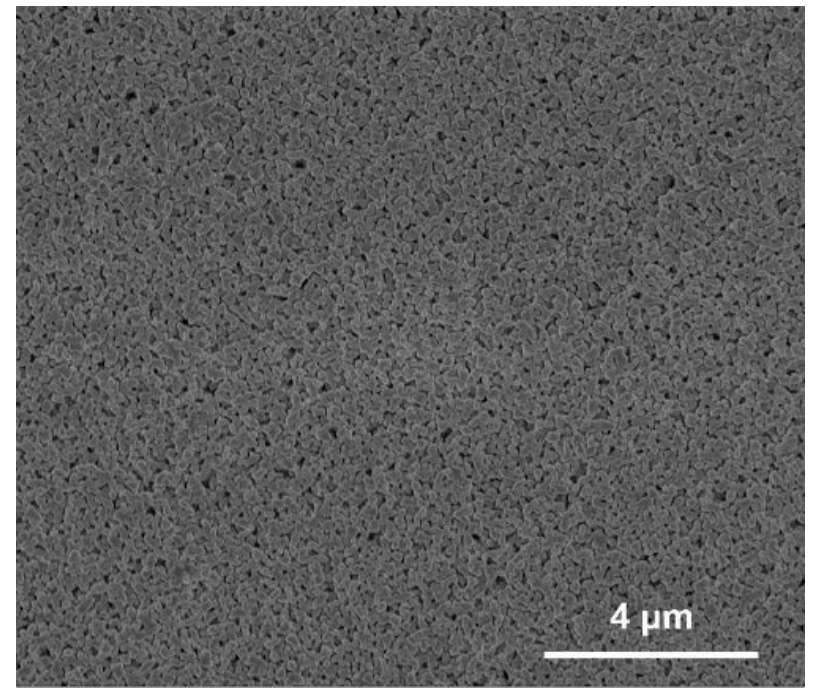

Figure S1. SEM image of cleaned porous $\alpha-\mathrm{Al}_{2} \mathrm{O}_{3}$ substrate. 
SI-2 Characterization of Co-based gel layer obtained by drying at $120{ }^{\circ} \mathrm{C}$
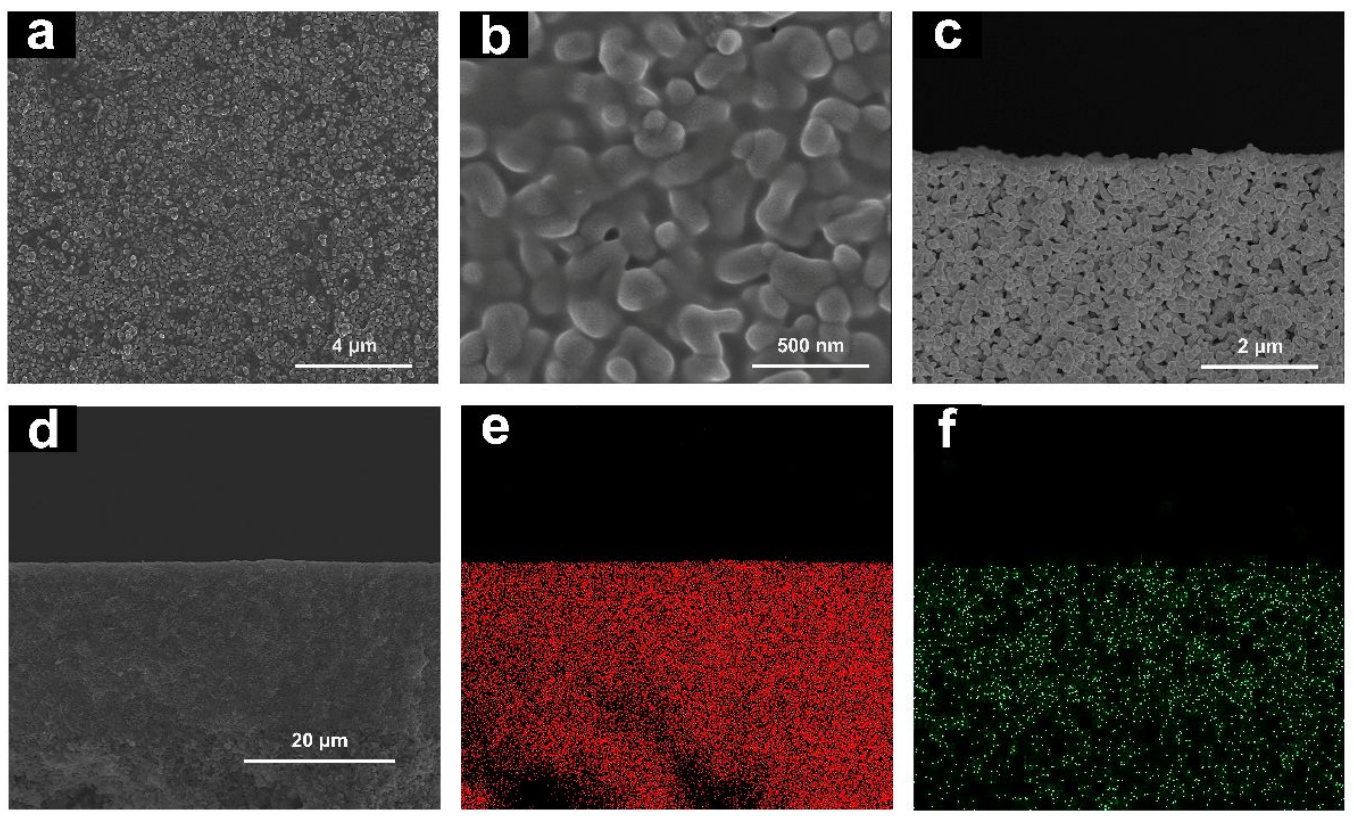

Figure S2. SEM images of $(a, b)$ top and $(c, d)$ cross-sectional views of the Co-based gel layer prepared by drying at $120{ }^{\circ} \mathrm{C}$ for $2 \mathrm{~h}$; (e, f) EDXS patterns of the Co-based gel layer prepared by drying at $120{ }^{\circ} \mathrm{C}$ for $2 \mathrm{~h}$ (color code: $\mathrm{red}=\mathrm{Al}$, green $=\mathrm{Co})$. 
SI-3 Plausible chemical reactions occurring in Co-based gel layer

Possible chemical reactions occurring in Co-based gel layer during drying were shown as follow:

$$
\begin{aligned}
& 2 \mathrm{Co}\left(\mathrm{CH}_{3} \mathrm{COO}\right)_{2}+\mathrm{H}_{2} \mathrm{O} \rightleftharpoons \mathbf{C o}(\mathbf{O H})\left(\mathbf{C H}_{3} \mathbf{C O O}\right)+\mathrm{CH}_{3} \mathrm{COOH}+\mathrm{Co}^{2+}+2 \mathrm{CH}_{3} \mathrm{COO}^{-} \\
& \mathrm{Co}(\mathrm{OH})\left(\mathrm{CH}_{3} \mathrm{COO}\right)+\mathrm{H}_{2} \mathrm{O} \rightleftharpoons \mathbf{C o}(\mathbf{O H})_{2}+\mathrm{CH}_{3} \mathrm{COOH} \\
& \mathrm{Co}^{2+}+\mathrm{HOCH}_{2} \mathrm{CH}_{2} \mathrm{NH}_{2} \rightleftharpoons\left[\mathbf{C o}(\mathbf{O H}) \mathbf{C H}_{2} \mathbf{C H}_{2} \mathbf{N H}_{2}\right]^{2+} \\
& \mathrm{Co}(\mathrm{OH})_{2}+\cdots+\mathrm{Co}(\mathrm{OH})_{2} \rightleftharpoons\left[-\mathbf{H}-\mathbf{O}-\mathbf{C o}-\mathbf{O}-\mathrm{H}_{-}\right]_{\mathbf{n}}+\mathrm{H}_{2} \mathrm{O}
\end{aligned}
$$


SI-4 Characterization of ZIF-67 membrane prepared by in situ supercritical growth in $\mathrm{scCO}_{2}$ environments
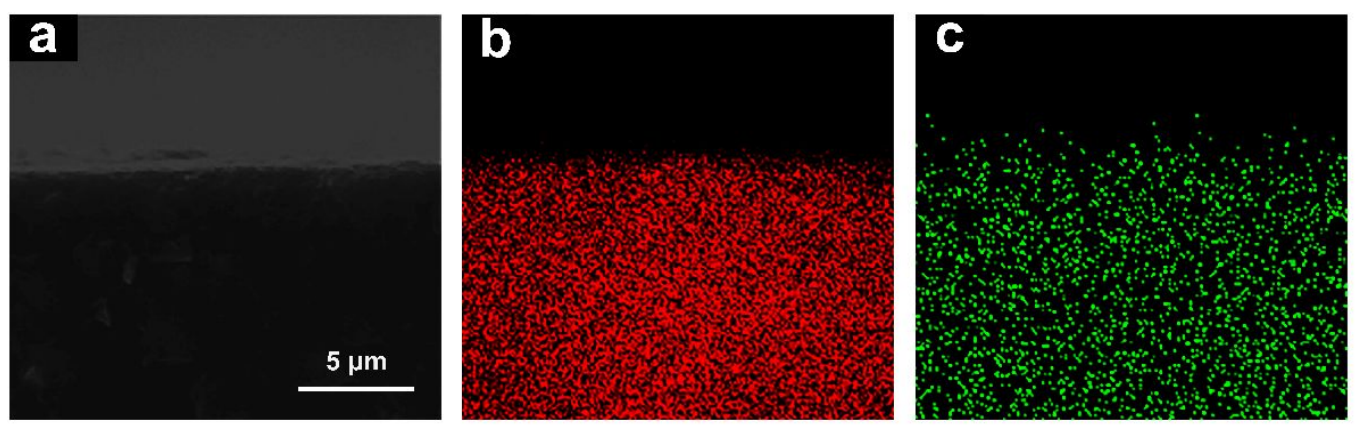

Figure S3. (a) Cross-sectional SEM image and (b, c) EDXS patterns of the ZIF-67 membrane prepared by in situ supercritical growth in $\mathrm{scCO}_{2}$ environments (color code: red $=\mathrm{Al}$, green $=\mathrm{Co}$ ). 


\section{SI-5 Preparation of ZIF-67 membrane via solution-based protocol}

The procedure for preparation of ZIF-67 membrane via solution-based protocol was as follow: Initially, $1.232 \mathrm{~g}$ 2-mIm was added into $30 \mathrm{~mL}$ DI water and stirred for $30 \mathrm{~min}$ to obtain precursor solution. Subsequently, the Co-based gel layer-modified $\alpha-\mathrm{Al}_{2} \mathrm{O}_{3}$ porous substrate was placed horizontally facing down in a Teflon-lined stainless steel vessel filled with the above precursor solution. In the next step, the autoclave was kept at $50{ }^{\circ} \mathrm{C}$ for $24 \mathrm{~h}$. After cooling down, prepared membrane as well as purple precipitates were taken out of the vessel and washed wit DI $\mathrm{H}_{2} \mathrm{O}$. Finally, the membrane was dried under vacuum at $50{ }^{\circ} \mathrm{C}$ for $12 \mathrm{~h}$ before use. 
SI-6 Characterization of ZIF-67 layer obtained by conventional solution-based protocol
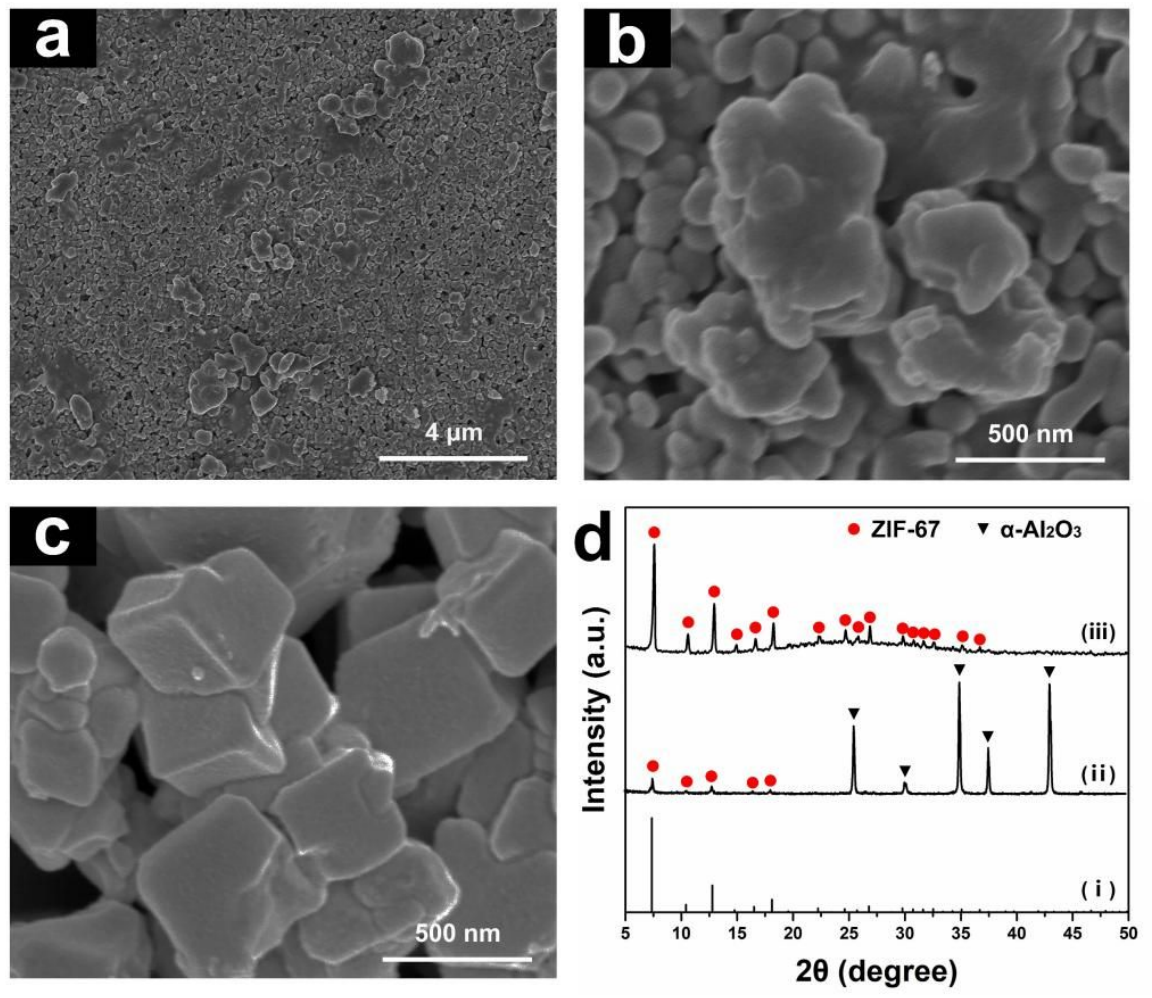

Figure S4. (a, b) SEM images of the ZIF-67 layer prepared with conventional solution-based protocol. (c) SEM image of recovered ZIF-67 particles after solution-based treatment. (d) Corresponding XRD patterns of ( $\mathrm{i}$ ) simulated ZIF-67, ( ii ) ZIF-67 layer and (iii) recovered ZIF-67 particles obtained by conventional solution-based protocol. 


\section{SI-7 Investigation of structural stability of Co-based gel powders under mild reaction conditions}

Co-based gel powders were placed in a Teflon-lined stainless steel vessel filled with $30 \mathrm{~mL}$ DI water. Subsequently, the autoclave was kept at $50{ }^{\circ} \mathrm{C}$ for $24 \mathrm{~h}$. After cooling down, the precipitates were washed with DI water.

As shown in Figure S5, Co-based gel powders were collapsed after solution-based treatment.
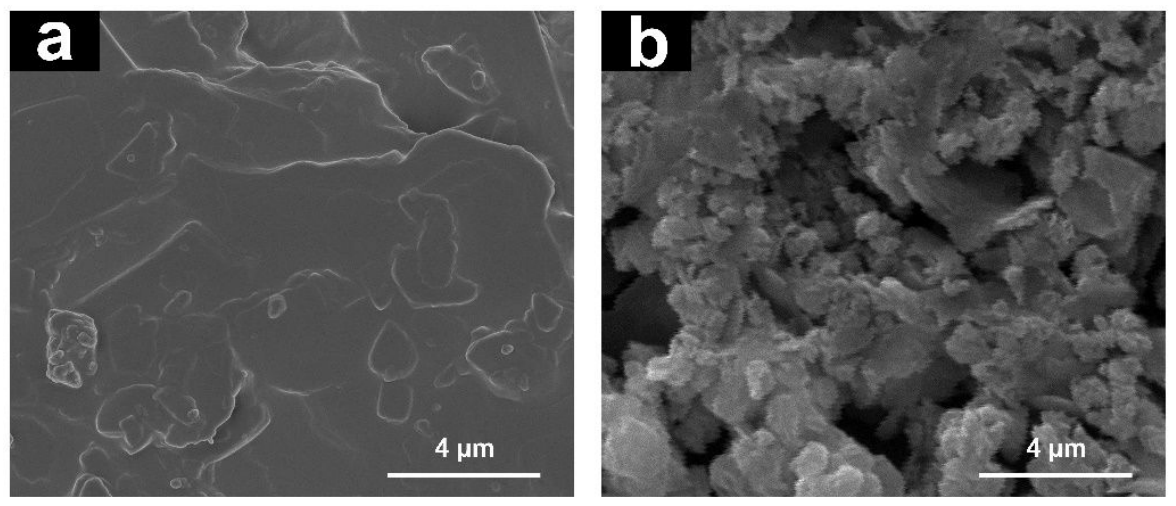

Figure S5. SEM images of (a) raw Co-based gel and (b) Co-based gel powders after solution-based treatment at $50{ }^{\circ} \mathrm{C}$ for $24 \mathrm{~h}$. 
SI-8 Gas separation performance of ZIF-67 membrane as a function of operating temperature
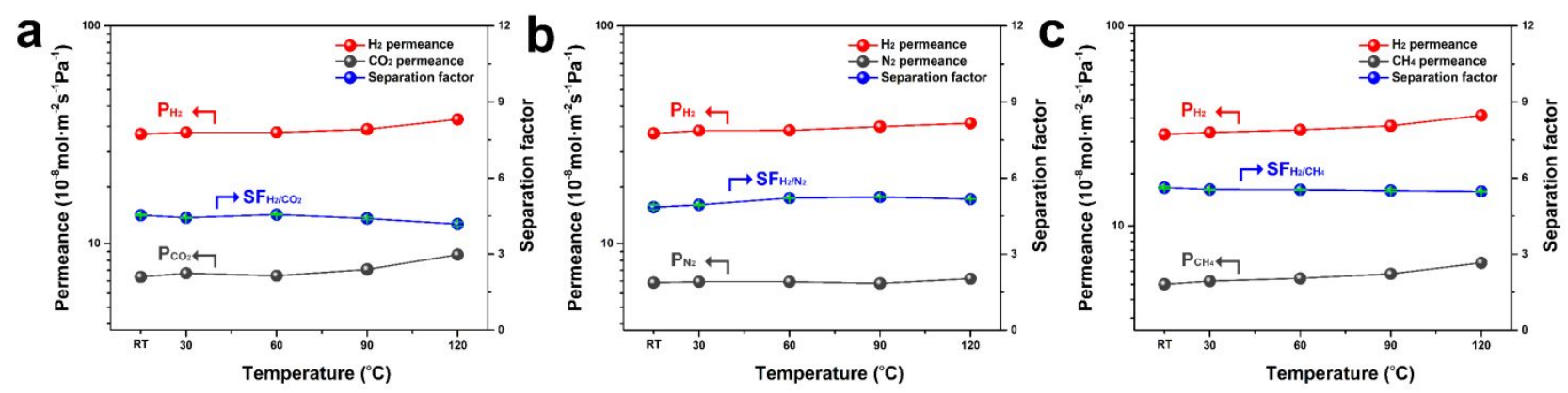

Figure S6. (a-c) Equimolar $\mathrm{H}_{2} / \mathrm{CO}_{2}, \mathrm{H}_{2} / \mathrm{N}_{2}$ and $\mathrm{H}_{2} / \mathrm{CH}_{4}$ separation performances of prepared ZIF-67 membrane as a function of operating temperature (ranging between $\mathrm{RT}$ and $120^{\circ} \mathrm{C}, \Delta \mathrm{P}=1 \mathrm{bar}$ ). 


\section{SI-9 Long-term stability of prepared ZIF-67 membrane}
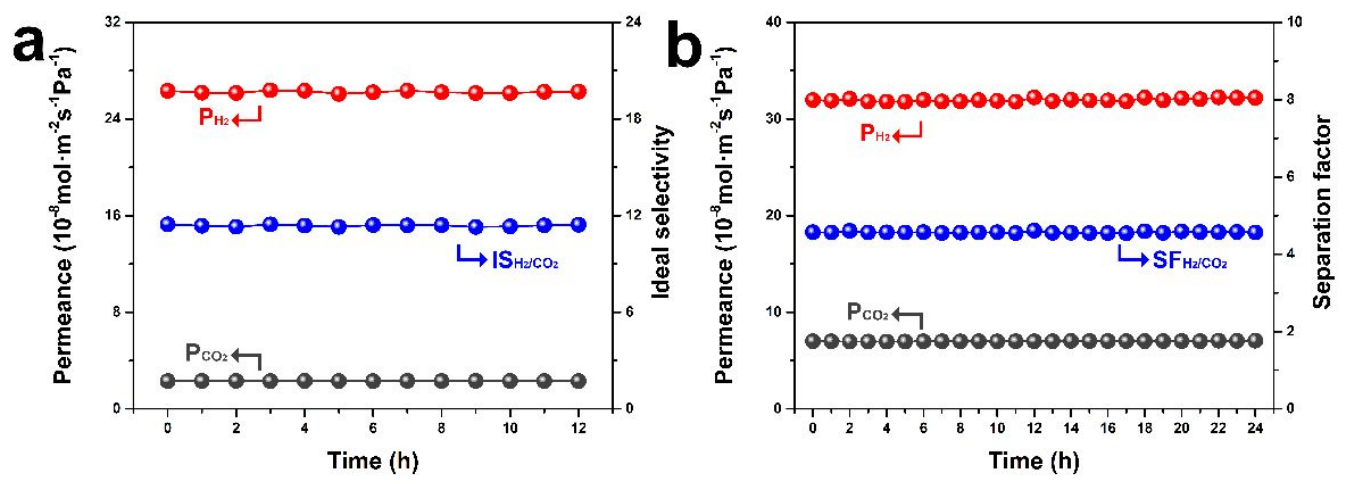

Figure S7. Long-term performance stability of ZIF-67 membrane towards (a) single $\mathrm{H}_{2} / \mathrm{CO}_{2}$ and (b) equimolar $\mathrm{H}_{2} / \mathrm{CO}_{2}$ gas mixture under ambient conditions. 
SI-10 Characterization of ZIF-67 membranes obtained by in situ supercritical growth in $\mathrm{scCO}_{2}$ environments with recovered $2-\mathrm{mIm}$ powders
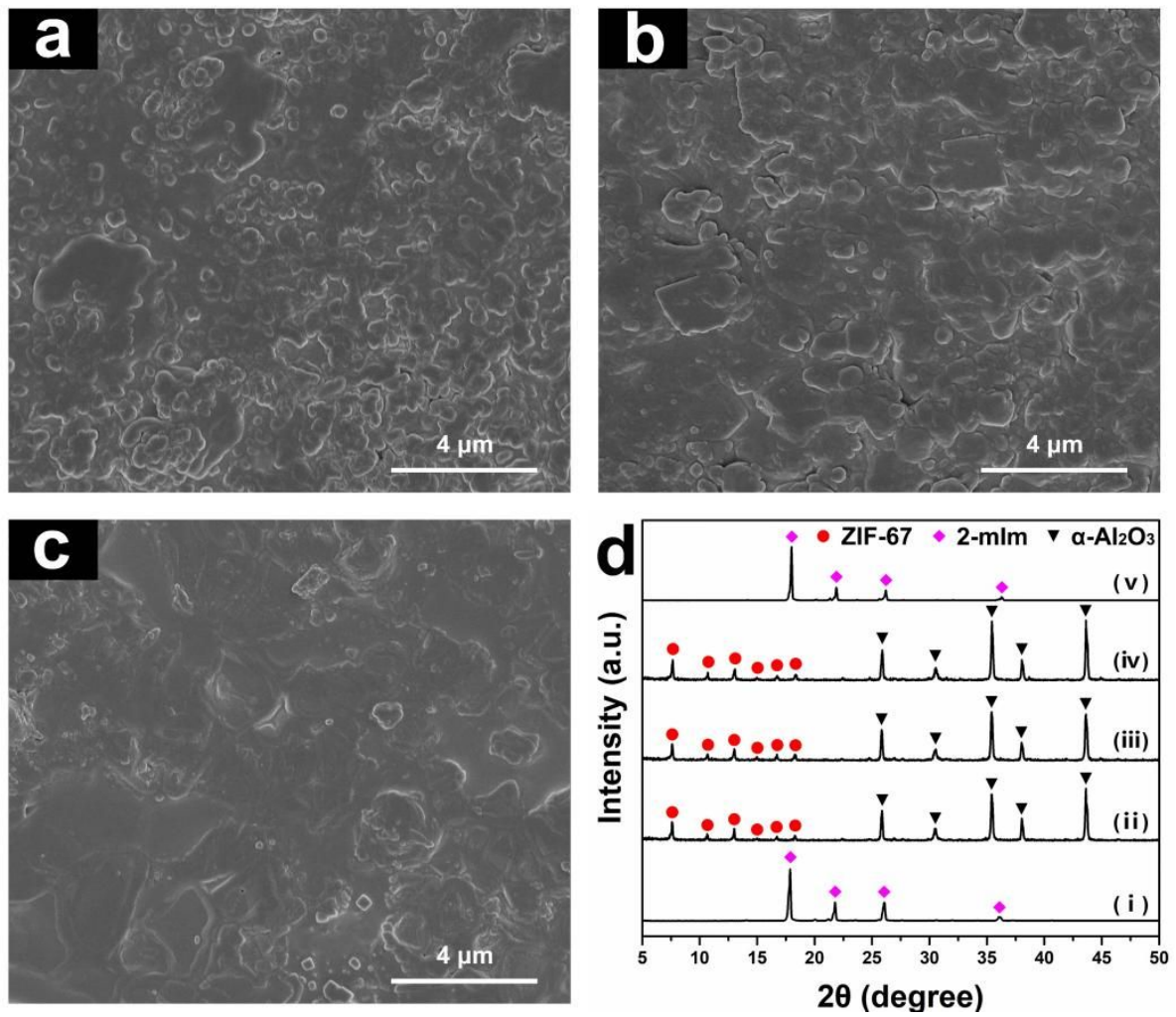

Figure S8. SEM images of ZIF-67 membranes obtained by in situ supercritical growth in $\mathrm{scCO}_{2}$ environments with 2-mIm powders recovered for (a) 2 times, (b) 3 times and (c) 4 times. (d) XRD patterns of (i) raw 2-mIm ligands, corresponding ZIF-67 membranes prepared with 2-mIm powders recovered for ( ii ) 2 times, (iii) 3 times, (iv ) 4 times, and ( $v$ ) finally recovered 2-mIm powders. 
SI-11 Characterization of recovered 2-mIm powders
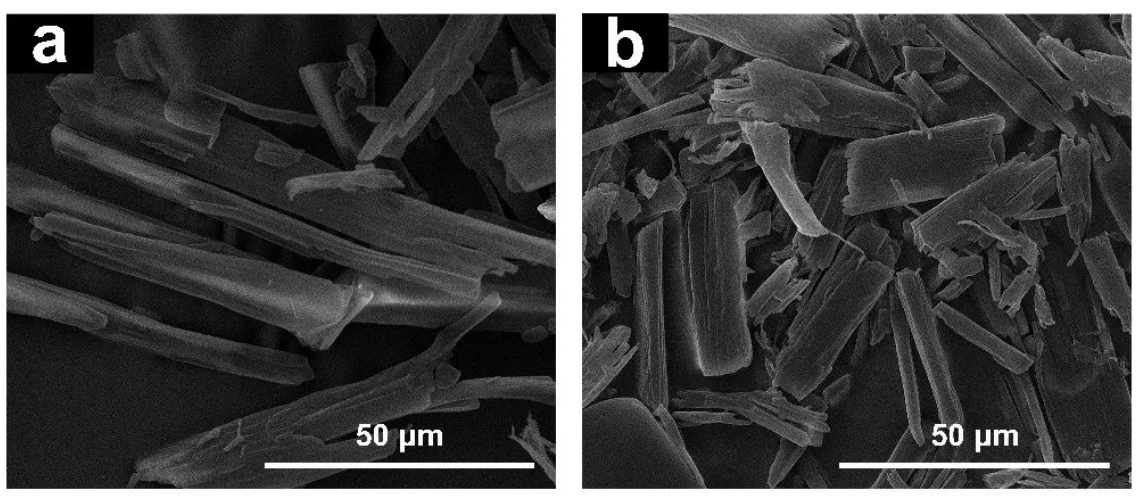

Figure S9. SEM images of (a) raw 2-mIm powders and (b) finally recovered 2-mIm powders. 
SI-12 Characterization of Co-based gel layer drying at room temperature
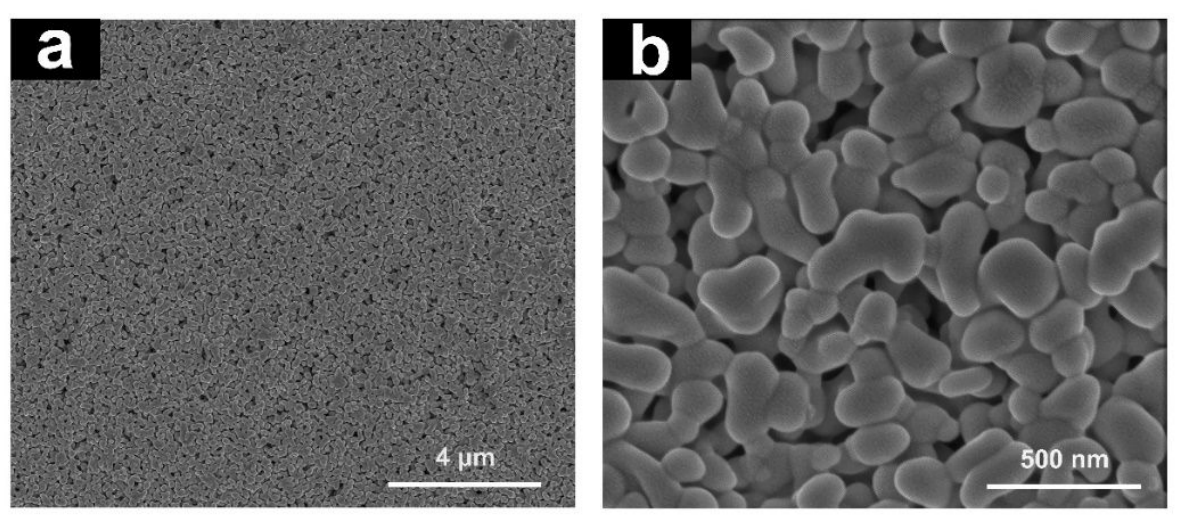

Figure S10. (a-b) SEM images of Co-based gel layer drying at room temperature. 
SI-13 Characterization of Co-based gel layer drying at $240{ }^{\circ} \mathrm{C}$
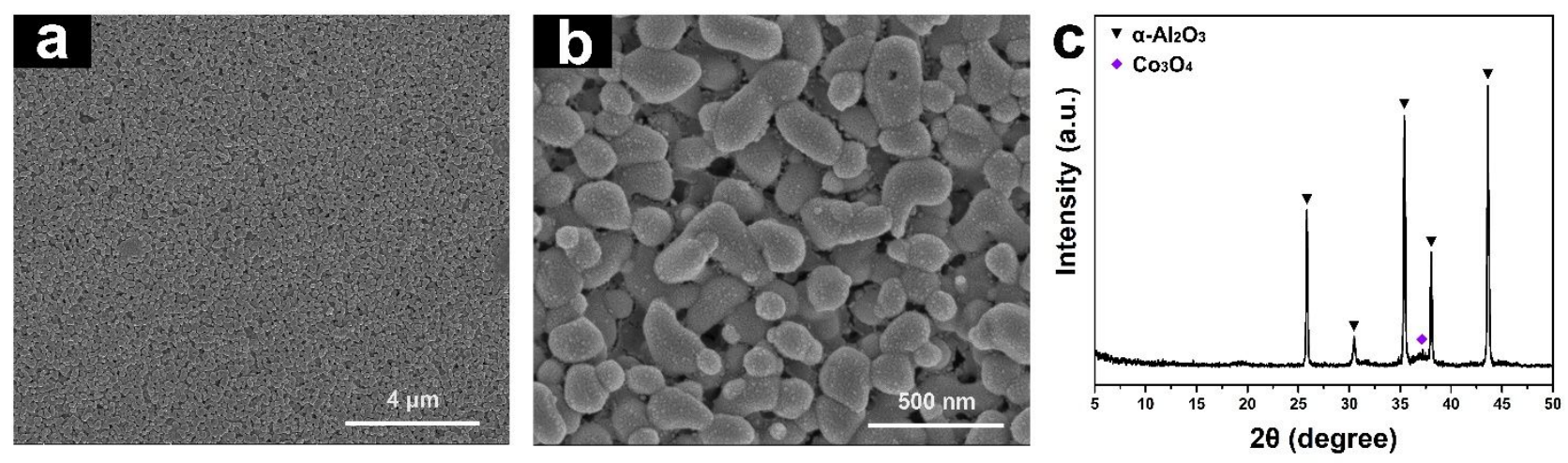

Figure S11. (a-b) SEM images and (c) XRD pattern of Co-based gel layer drying at $240{ }^{\circ} \mathrm{C}$. 
SI-14 Characterization of ZIF-67 membranes obtained with Co-based gel layers drying at different temperature

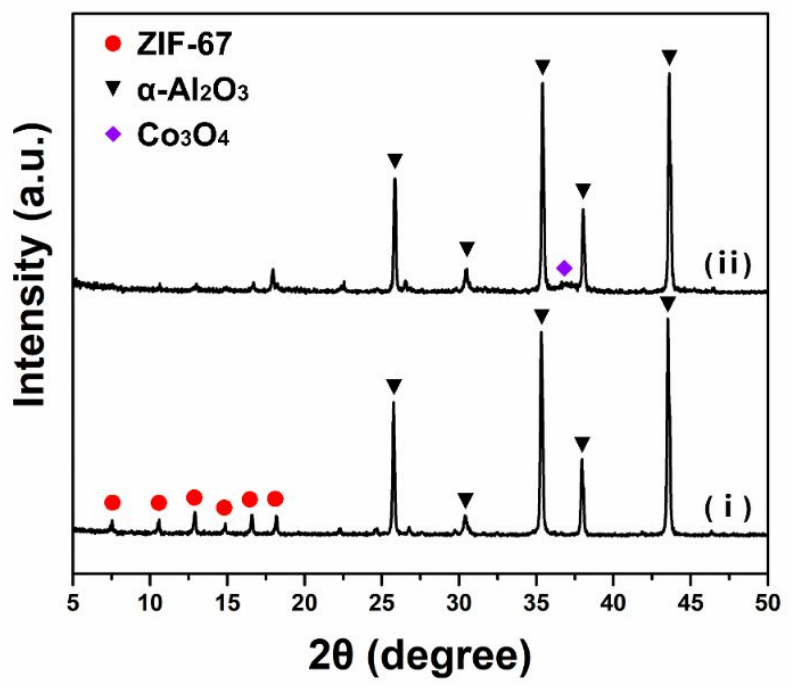

Figure S12. XRD patterns of ZIF-67 membranes prepared with Co-based gel layers drying at (i) RT and (ii) $240^{\circ} \mathrm{C}$. 
SI-15 Characterization of ZIF-67 membranes obtained with different SCF processing

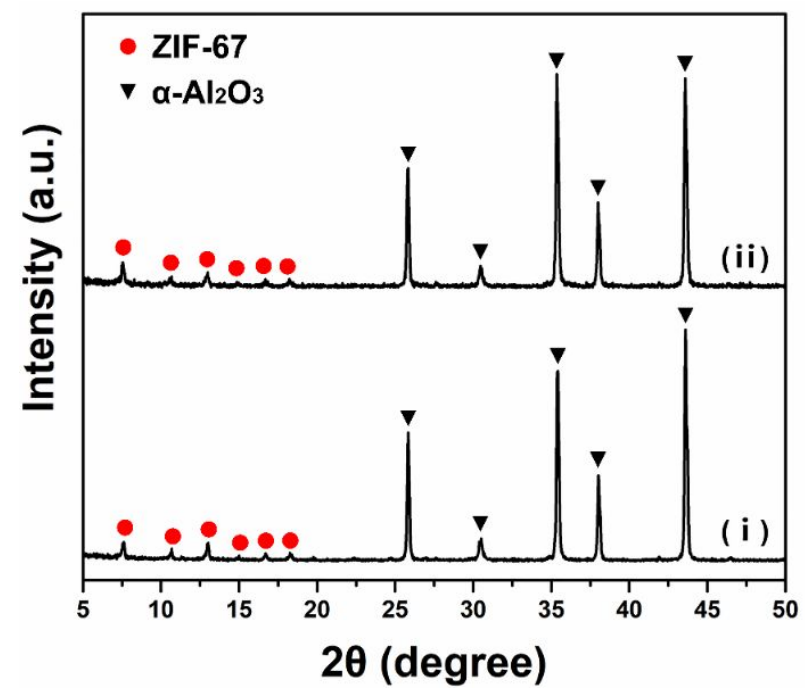

temperature

Figure S13. XRD patterns of ZIF-67 membranes prepared at SCF processing pressure of 100 bar and temperature of (i) $35^{\circ} \mathrm{C}$ and (ii) $65^{\circ} \mathrm{C}$. 
SI-16 Characterization of ZIF-67 membranes obtained with different SCF processing pressure

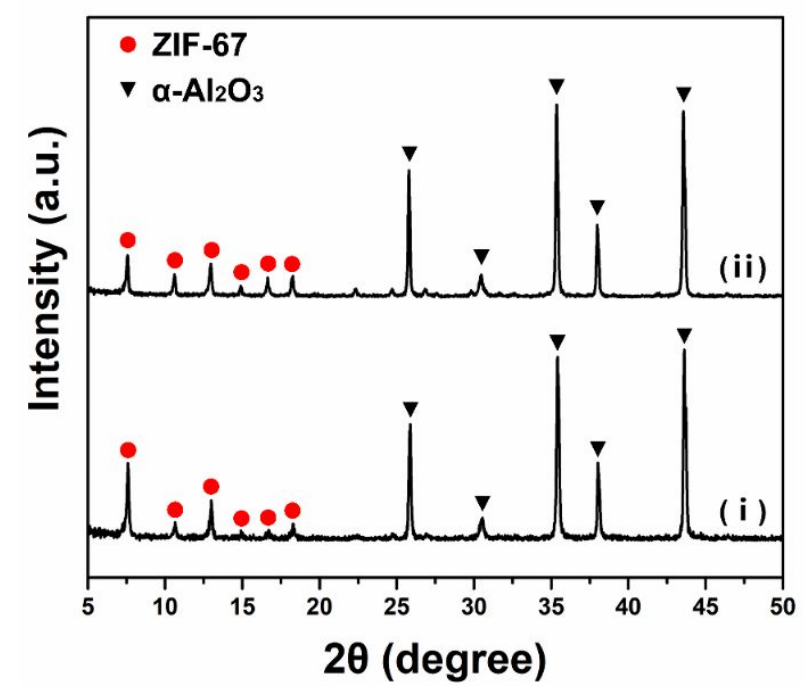

Figure S14. XRD patterns of ZIF-67 membranes prepared at SCF processing temperature of $95{ }^{\circ} \mathrm{C}$ and pressure of (i) 300 bar and (ii) 500 bar. 
SI-17 Viscosity of $\mathrm{scCO}_{2}$ as a function of temperature and pressure

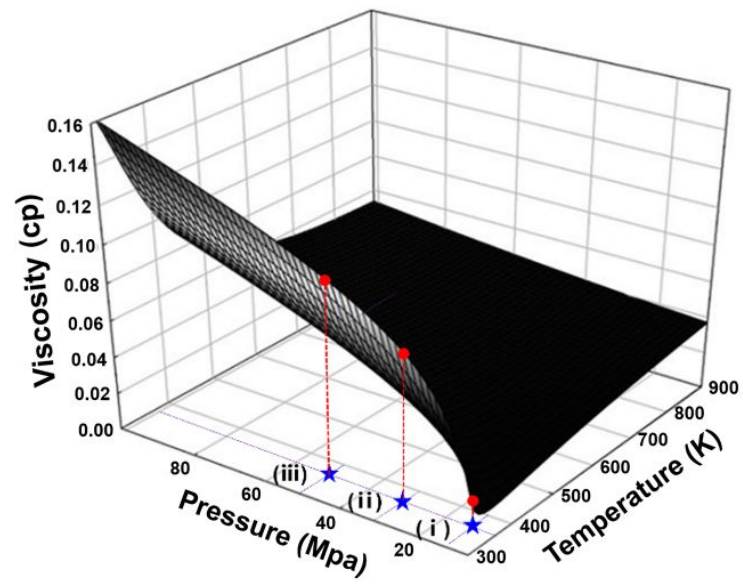

Figure S15. Illustration of viscosity of $\mathrm{scCO}_{2}$ as a function of temperature and pressure: ( $\mathrm{i}$ ) $95{ }^{\circ} \mathrm{C}$ and 100 bar, (ii ) $95^{\circ} \mathrm{C}$ and 300 bar, and (iii ) $95^{\circ} \mathrm{C}$ and 500 bar ${ }^{42}$. 
SI-18 Gas separation performances of ZIF-67 membranes in the literature

Table S1. $\mathrm{H}_{2} / \mathrm{CO}_{2}$ separation performances of ZIF-67 membranes reported in the literature.

\begin{tabular}{|c|c|c|c|c|c|c|c|c|}
\hline Membrane & Substrate & Buffer layer & Synthetic method & $\begin{array}{c}\text { Thickness } \\
(\mu \mathrm{m})\end{array}$ & Permeance & Permeability & $\mathrm{S}\left(\mathrm{H}_{2} / \mathrm{CO}_{2}\right)$ & Ref. \\
\hline ZIF-67 & a-alumina support & cobalt-based nanosheets & solvothermal & 3.0 & 148.0 & 13269.6 & 16.8 & $(30)$ \\
\hline ZIF-67 & a-alumina tubes & $\begin{array}{c}\text { carbonate hydroxide } \\
\text { nanowire }\end{array}$ & solvothermal & 1.7 & 55.9 & 2840.1 & 5.2 & $(29)$ \\
\hline ZIF-67 & $\begin{array}{c}\text { stainless steel } \\
\text { support }\end{array}$ & $\mathrm{Co}(\mathrm{OH})_{2}$ nanosheets & solvent-free growth & 4.0 & 5.6 & 669.5 & 9.3 & $(24)$ \\
\hline ZIF-67 & $\begin{array}{c}\text { stainless steel } \\
\text { support }\end{array}$ & $\mathrm{Co}(\mathrm{OH})_{2}$ nanosheets & solvothermal & $\sim 16.9$ & 14.7 & 7424.7 & 8.2 & $(31)$ \\
\hline ZIF-67 & $\begin{array}{c}\mathrm{Co}^{2+} @ \text { cPIM-1 } \\
\text { modified } \alpha-\mathrm{Al}_{2} \mathrm{O}_{3} \\
\text { disks }\end{array}$ & I & solvothermal & $\sim 12.0$ & 62.0 & 22235.5 & 15.1 & (34) \\
\hline ZIF-67 & a-alumina support & cobalt-based gel & $\begin{array}{l}\text { supercritical fluid } \\
\text { processing }\end{array}$ & 5.1 & 26.3 & 4004.3 & 11.4 & $\begin{array}{l}\text { This } \\
\text { work }\end{array}$ \\
\hline
\end{tabular}

Permeance: $\times 10^{-8} \mathrm{~mol} \cdot \mathrm{m}^{-2} \cdot \mathrm{s}^{-1} \cdot \mathrm{Pa}^{-1}$.

Permeability: barrer $\left(1\right.$ barrer $\left.=10^{-10} \mathrm{~cm}^{3}(\mathrm{STP}) \mathrm{cm}^{-1} \mathrm{~s}^{-1} \mathrm{cmHg}-1=3.346 \times 10^{-16} \mathrm{~mol} \cdot \mathrm{m} \cdot \mathrm{m}^{-2} \cdot \mathrm{s}^{-1} \cdot \mathrm{Pa}^{-1}\right)$. 